\title{
Characterization of Impact Deformation Behavior of a Thermally Aged Duplex Stainless Steel by EBSD
}

\author{
Gang Liu ${ }^{1}$ Shi-Lei $\mathrm{Li}^{1} \cdot$ Hai-Long Zhang ${ }^{1} \cdot$ Xi-Tao Wang ${ }^{2} \cdot$ Yan-Li Wang ${ }^{1}$ \\ Received: 29 September 2017/Revised: 5 January 2018/Published online: 21 February 2018 \\ (C) The Chinese Society for Metals and Springer-Verlag GmbH Germany, part of Springer Nature 2018
}

\begin{abstract}
The effect of thermal aging on phase transformation and impact toughness of an as-cast duplex stainless steel was investigated at room temperature. After long-term thermal aging, the impact toughness decreases significantly and the cracks initiate and propagate more easily. The plastic deformation ability of the ferrite phase decreases after thermal aging, which leads to the degradation of impact toughness. High stress concentration occurs on the grain boundaries of the austenite phase in the aged materials. Meanwhile, high-stress concentration areas are also observed in the austenite phase near the grain boundaries. After long-term thermal aging, pinned dislocations in ferrite and along phase boundaries lead to the high stress concentration. Micro-cracks preferentially initiate in the ferrite phase and propagate via separation of phase boundaries. The blocking influences of spinodal decomposition precipitates and G-phase precipitates are stronger than the effect of grain boundaries and phase boundaries on the dislocation movement.
\end{abstract}

Keywords Duplex stainless steel $\cdot$ Thermal aging $\cdot$ Charpy impact toughness $\cdot$ EBSD

\section{Introduction}

Duplex stainless steels (DSS) are used extensively in chemical, nuclear and oil industries due to their good mechanical properties, excellent welding performance and high resistance to stress corrosion cracking $[1,2]$. These steels have a duplex microstructure consisting of ferrite and austenite. However, it has been recognized that the ferrite phase in duplex stainless steels is susceptible to embrittlement due to the precipitation of the chromium-enriched phase [3]. The embrittlement occurs in the ferrite phase in duplex stainless steels when the material is aged at $300-500{ }^{\circ} \mathrm{C}[4,5]$. Some studies indicate that the embrittlement of the duplex stainless steels is attributed to

Available online at http://link.springer.com/journal/40195

Yan-Li Wang

wangyl@ustb.edu.cn

1 State Key Laboratory for Advanced Metals and Materials, University of Science and Technology Beijing, Beijing 100083, China

2 Collaborative Innovation Center of Steel Technology, University of Science and Technology Beijing, Beijing 100083, China spinodal decomposition of the ferrite phase [6]. Up to now, several groups have studied the fracture toughness [7], tensile strength [8,9], fatigue resistance [10] and corrosion resistance [11] of the thermally aged DSS.

The elastic and plastic deformation behaviors are well recognized in certain austenite phase with the face-centered cubic (FCC) structure and ferrite phase with the bodycentered cubic (BCC) structure [12].

For the aged CF8M duplex stainless steels, dimples and cleavage are typical fracture modes at room temperature, and a mixture of dimples, cleavage and grain boundary separation is the fracture mode for the steels aged at higher temperature [13]. The embrittlement of the ferrite phase causes the decline of crack propagation energy in the ferrite phase, and the wavy profiles of impact fracture become flatter with aging time $[14,15]$. Cracking mechanism in the thermally aged duplex stainless steels consists of the formation of cleavage in the ferrite phase and its propagation via separation of ferrite-austenite interphase [16].

For the 2205 duplex stainless steel aged at $400-500{ }^{\circ} \mathrm{C}$, the ferrite phase exhibits a tendency of quasi-cleavage failure and the austenite phase shows a change from normal dimple rupture to tearing fracture [17]. The reduction in impact fracture energy after thermal aging is associated with the formation of shallow ductile dimples and cleavage 
facets on the fracture surfaces of $316 \mathrm{~L}$ duplex stainless steels [18]. The fracture of SS 304L welds aged at $365{ }^{\circ} \mathrm{C}$ for $20,000 \mathrm{~h}$ has changed from typical ductile failure to mixed mode of brittle and ductile failures [19].

Although numerous studies make an effort on the deformation behavior and the crack initiation mechanism, crack initiation site in the aged materials is still not clear. In the present study, we conduct a Charpy impact test of aged DSS to understand the mechanical properties and the crack initiation mechanism of the aged DSS at room temperature. The plastic deformation and fracture behavior are investigated after impact test. The role of the ferriteaustenite phase boundaries is clarified.

\section{Experimental}

The material studied was statically cast Z3CN20-09M DSS cut from the pressurized water reactor coolant piping. The steel was solution treated at $1100{ }^{\circ} \mathrm{C}$ for $8 \mathrm{~h}$ before water quenching. Thermal aging of the steel was carried out at $400{ }^{\circ} \mathrm{C}$ up to $10,000 \mathrm{~h}$. The chemical compositions of the steel are listed in Table 1. As shown in Fig. 1, the backscattered electron (BSE) image of the steel presents morphology of ferrite phases (dark areas) distributed in the austenite matrix. The volume fraction of the ferrite in the as-cast state is about $15 \%$.

Charpy V-notch impact test was conducted on the ascast and aged samples at room temperature. The size for the Charpy impact specimen was $10 \mathrm{~mm} \times 10 \mathrm{~mm} \times$ $55 \mathrm{~mm}$ with a V-notch (depth $2 \mathrm{~mm}$, notch radius $0.25 \mathrm{~mm}$, notch angle $45^{\circ}$ ) at the center. The impact test was conducted according to the French design and construction rules for mechanical components of pressurized water reactor (PWR) nuclear islands (RCC-M). After the impact test, the fracture surfaces were examined using scanning electron microscope (SEM). In addition, longitudinal section morphologies near the fractures were investigated using electron backscattered diffraction (EBSD). Before measurement, the specimens were mechanically ground with silicon carbide paper to grade 2000 and polished with diamond paste ( 1 and $0.25 \mathrm{~mm}$ ).

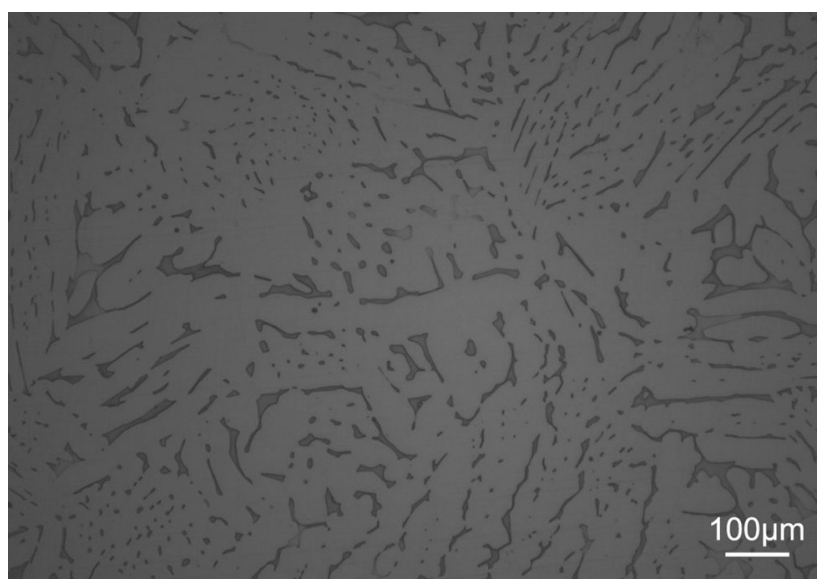

Fig. 1 BSE image of Z3CN20 09M DSS

Finally, they were electro-polished to remove the hardened layer using a voltage of $20 \mathrm{~V}$ for $30 \mathrm{~s}$ in a solution of $5 \%$ perchloric acid $\left(\mathrm{HClO}_{4}\right)-95 \%$ ethanol $\left(\mathrm{C}_{2} \mathrm{H}_{5} \mathrm{OH}\right)$.

The compositions of the ferrite and austenite phases in the steel were detected by an electron probe micro-analyzer (EPMA, JEOL JXA 8100, Japan). EBSD analysis was carried out on a SEM (Zeiss Auriga, Germany) equipped with EBSD instrument (HKL, Oxford, England). Impact fracture and surface characteristics were observed by SEM.

\section{Results and Discussion}

\subsection{Charpy Impact Test}

The impact energies of the specimens change a lot with aging time, which are 271.4 and $126.9 \mathrm{~J}$ for unaged and aged for $10,000 \mathrm{~h}$ specimen. The decrease in total impact energy indicates that the cracks initiate and propagate more easily after thermal aging.

Figure 2 shows the impact fracture morphologies of the unaged and aged samples. As shown in Fig. 2a, some secondary micro-cracks are observed on the surface of unaged specimens. The SEM morphology of the unaged specimen shows ductile fracture feature with many fine dimple, as shown in Fig. 2b. For the aged specimens, some

Table 1 Chemical compositions of Z3CN20-09M DSS (wt $\%$ )

\begin{tabular}{|c|c|c|c|c|c|c|c|c|c|c|c|}
\hline Element & $\mathrm{Cr}$ & $\mathrm{Ni}$ & $\mathrm{Mn}$ & $\mathrm{Si}$ & $\mathrm{C}$ & $S$ & $\mathrm{P}$ & $\mathrm{Cu}$ & Co & Mo & $\mathrm{Fe}$ \\
\hline RCC-M ${ }^{a}$ & $19.0-21.0$ & $8.0-11$ & $\leq 1.150$ & $\leq 1.50$ & $\leq 0.040$ & $\leq 0.015$ & $\leq 0.030$ & $\leq 1.00$ & $\leq 0.10$ & & \\
\hline Specimen & 20.12 & 9.52 & 1.11 & 1.13 & 0.028 & 0.0021 & 0.018 & 0.041 & 0.026 & 0.28 & Bal. \\
\hline Ferrite & 25.91 & 4.21 & 0.83 & 1.19 & - & - & - & - & - & 0.37 & Bal. \\
\hline Austenite & 19.98 & 10.36 & 0.97 & 1.06 & - & - & - & - & - & 0.20 & Bal. \\
\hline
\end{tabular}

${ }^{\mathrm{a}}$ The French design and construction rules for mechanical components of pressurized water reactor nuclear islands 

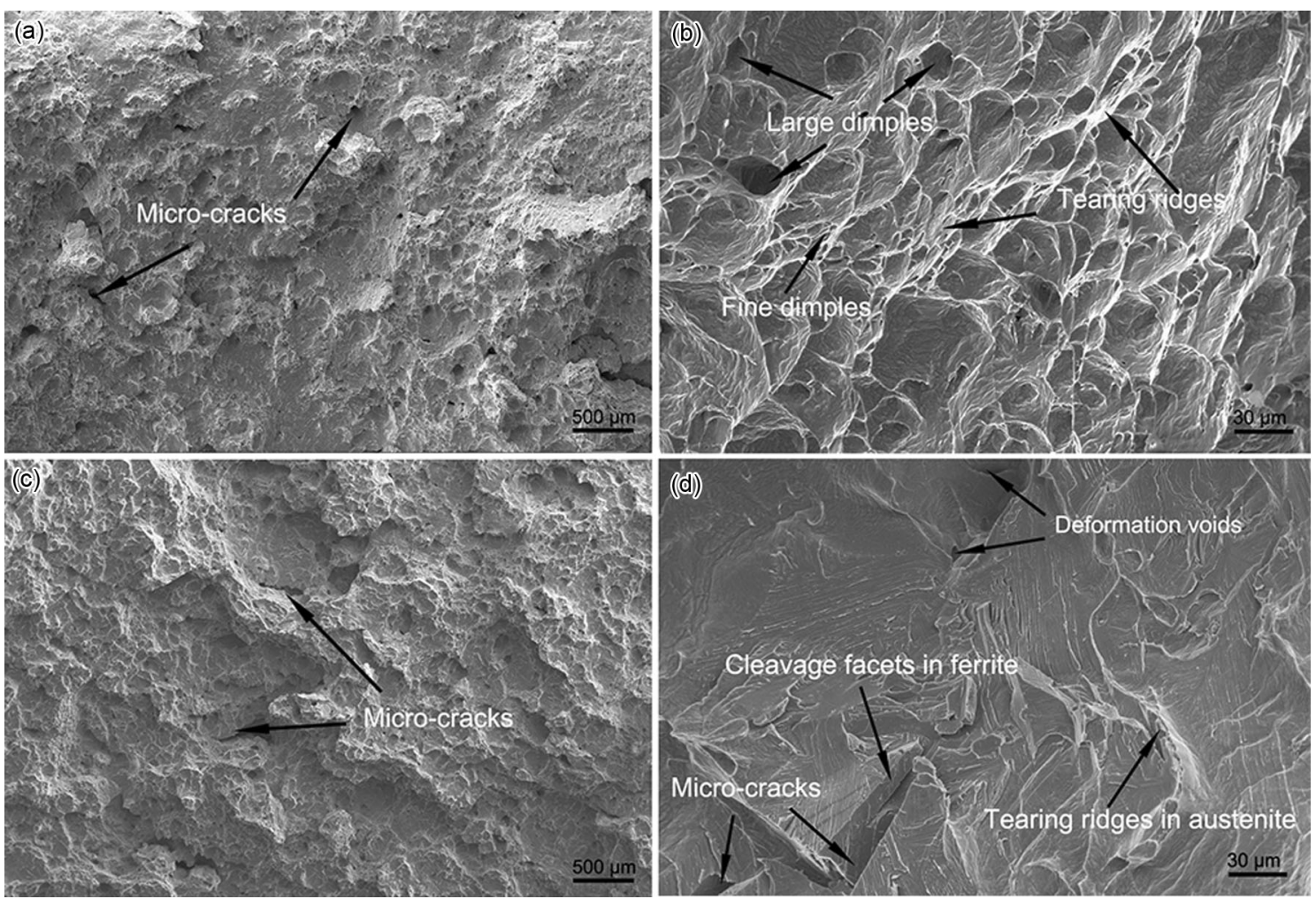

Fig. 2 Fracture morphologies of specimens aged at $400{ }^{\circ} \mathrm{C}$ for $\mathbf{a}, \mathbf{b} 0 \mathrm{~h}, \mathbf{c}, \mathbf{d ~} 10,000 \mathrm{~h}$

secondary micro-cracks are also observed, as shown in Fig. 2c. For the aged materials for $10,000 \mathrm{~h}$, a mixed fracture pattern of cleavage in the ferrite and tearing in the austenite is clearly identified as shown in Fig. 2d. As the deformation proceeds, micro-cracks preferentially initiate in ferrite phase and propagate via separation of phase boundaries. The deformation voids are also observed at the austenite grain boundaries. The hardened and embrittled ferrite phase will fracture on $\{001\}$ cleavage planes before the cracks go through the phase boundaries [20]. As shown in Fig. 2d, these regions in the yellow lines are related to the cleavage fracture in the ferrite grains with the same orientation. As the deformation proceeds, high-stress concentration areas in the aged ferrite grains could cause the tearing of surrounding austenite phases.

Figure 3 shows the longitudinal section morphologies near the fractures from the fractured impact specimens. Both the ferrite and the austenite phases have good deformation ability for the unaged materials. However, the plastic deformation ability of the samples decreases after long thermal aging, as shown in Fig. 3b. Three different areas along the vertical direction of notch are selected (each $1680 \mu \mathrm{m} \times 891 \mu \mathrm{m}$ in size). These areas correspond to three different stages of impact deformation, namely crack initiation region (IR), crack propagation region (IIR) and near final fracture region (IIIR).

\subsection{EBSD Analysis Near the Fractures}

The EBSD orientation maps present the change in microstructural features in the regions deformed differently, as shown in Fig. 4. The variance in color represents the development of local misorientation. As the deformation proceeds, the variance in either the grain orientation or the grain shape becomes more evident for unaged samples, as shown in Fig. 4a-c. Compared with the unaged samples, there is no obvious difference in color in the ferrite and austenite grains for the aged material, as shown in Fig. $4 d-$ f. In addition, the variance in overall color of certain grains near the fracture is also clearly identified for the aged sample.

The phase and grain boundary maps in the three regions deformed differently are shown in Fig. 5. For each map, thin black lines indicate low-angle boundaries $\left(5^{\circ}<\right.$ misorientation angle $\left.<15^{\circ}\right)$, thick black lines highangle boundaries $\left(15^{\circ}<\right.$ misorientation angle $\left.<45^{\circ}\right)$ and thick green lines higher-angle boundaries $\left(45^{\circ}<\right.$ misorientation angle). Ferrite and austenite phases are presented by red and gray colors, respectively.

In IR region, there is no obvious difference between the unaged and aged samples in the feature of both low-angle boundaries and other boundaries, as shown in Fig. 5a, d. As the deformation proceeds, a large number of low-angle and high-angle boundaries develop in the austenite grain for the 

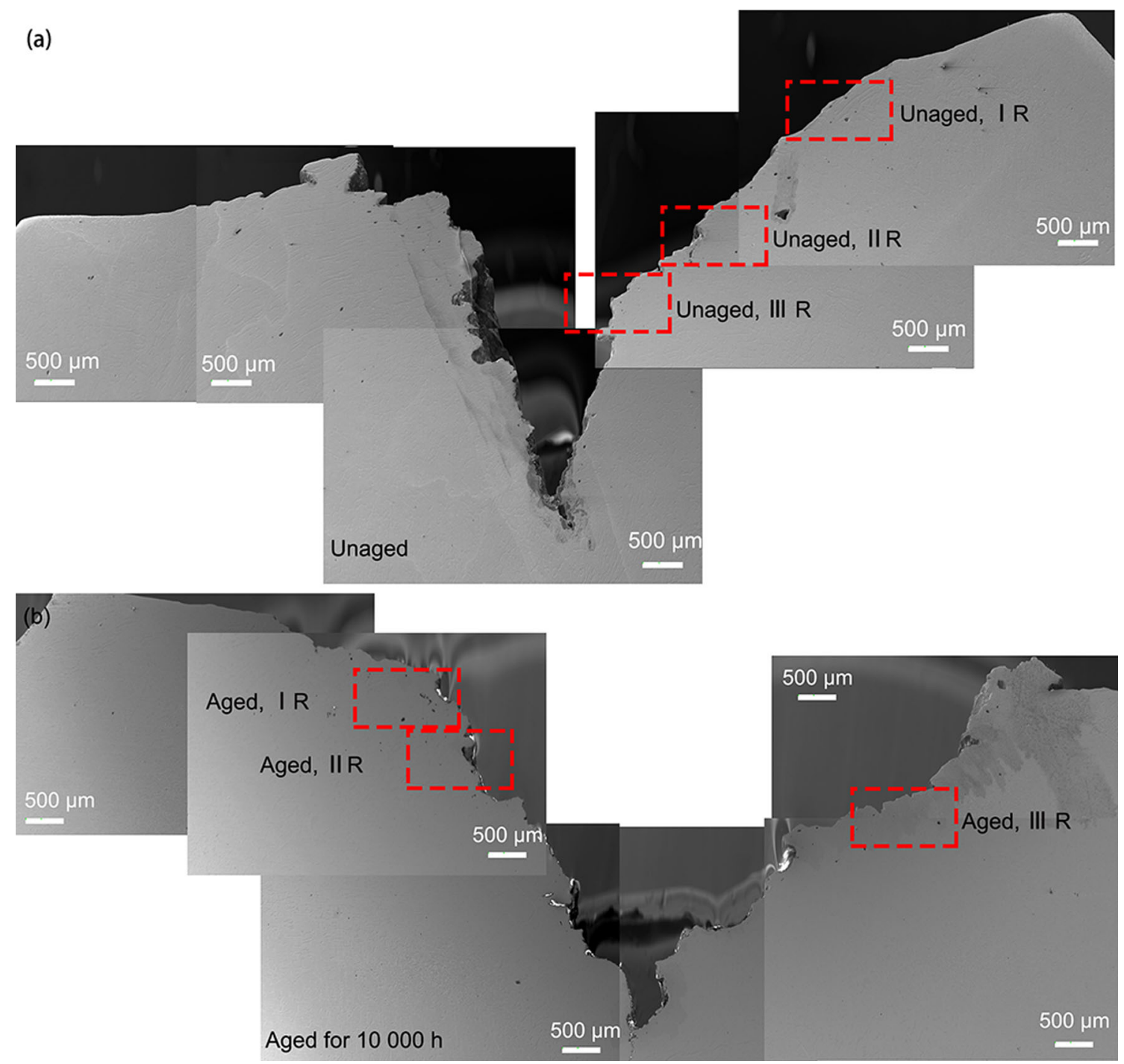

Fig. 3 Longitudinal section morphologies near the fracture of specimens aged at $400{ }^{\circ} \mathrm{C}$ for $\mathbf{a} 0 \mathrm{~h}, \mathbf{b} 10,000 \mathrm{~h}$

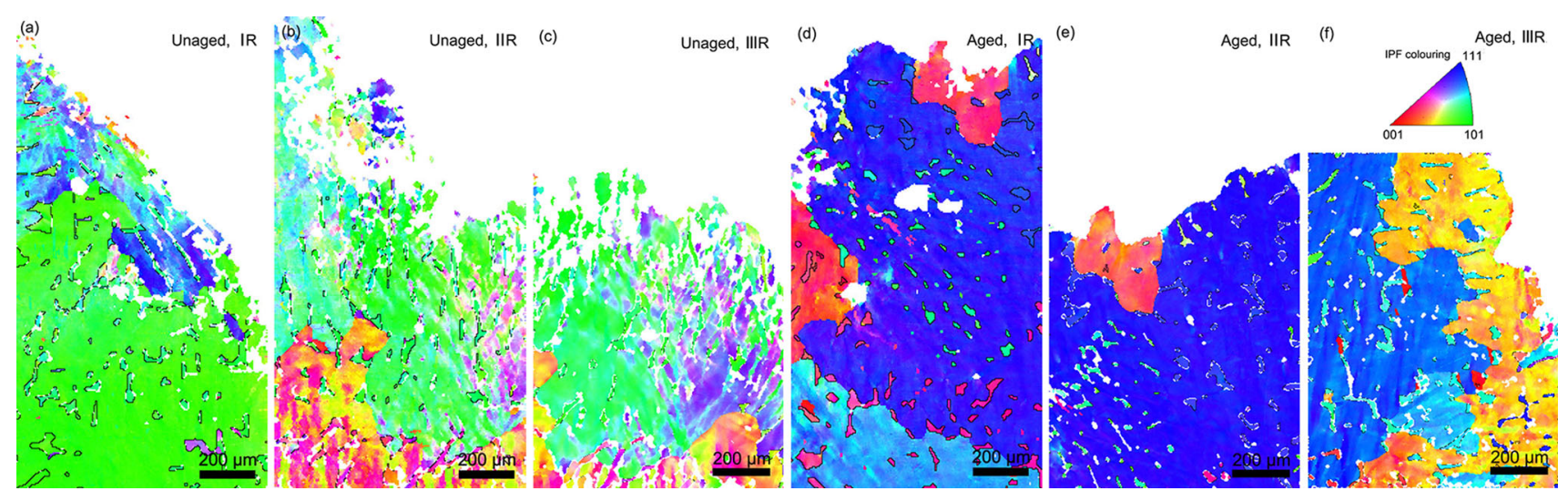

Fig. 4 EBSD orientation maps in three different deformation regions: $\mathbf{a}$ unaged at IR; $\mathbf{b}$ unaged at IIR; $\mathbf{c}$ unaged at IIIR; $\mathbf{d}$ aged for 10,000 $\mathrm{h}$ at IR; e aged for $10,000 \mathrm{~h}$ at IIR; f aged for $10,000 \mathrm{~h}$ at IIIR (red: $<001>$; blue: $<111>$; green: < $101>$; IPF: inverse pole figure)

unaged materials, as shown in Fig. 5b. A few high-angle boundaries are clearly identified in some unaged ferrite grains. Compared with the unaged samples, fewer lowangle and high-angle boundaries are observed in ferrite and 


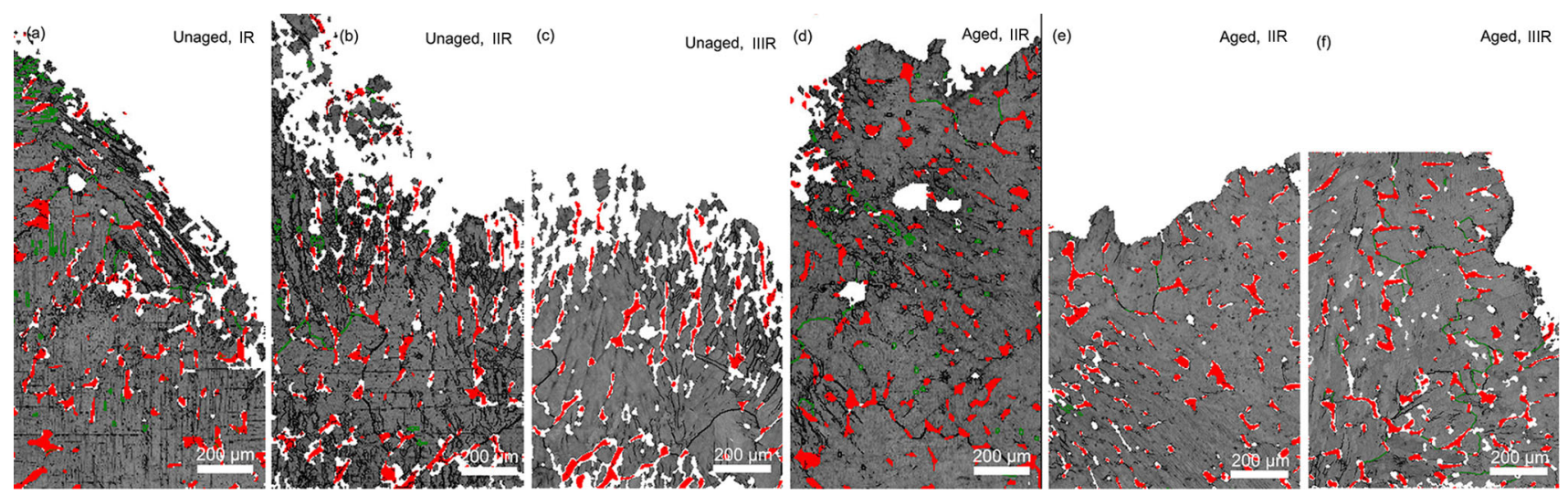

Fig. 5 Phase and grain boundary maps in three regions deformed differently: a unaged at IR; b unaged at IIR; $\mathbf{c}$ unaged at IIIR; d aged for $10,000 \mathrm{~h}$ at IR; $\mathbf{e}$ aged for $10,000 \mathrm{~h}$ at IIR; $\mathbf{f}$ aged for $10,000 \mathrm{~h}$ at IIIR (red areas: ferrite phase; fine black lines: $5^{\circ}-15^{\circ}$ small misorientation; thick black lines: $15^{\circ}-45^{\circ}$ intermediate misorientation; green lines: $>45^{\circ}$ large misorientation)

austenite grains for the thermally aged materials, as shown in Fig. 5e. As the deformation proceeds, the fraction of low-angle boundaries continuously decreases in both the austenite and the ferrite phases for the unaged materials, as shown in Fig. 5c. A few higher-angle boundaries are clearly identified in some aged ferrite grains. However, there are some higher-angle boundaries in IIIR region for the aged austenite phases, as shown in Fig. 5f. These thick green lines are likely related to the increase in the misorientation between neighboring austenite grains. As we know, the low-angle boundaries gradually evolve with strain. However, the impact strain of sample continuously decreases with the deformation. EBSD observations in Fig. 5 show that the fraction of low-angle boundaries continuously decreases with deformation.

The distribution of misorientation angle in different deformation regions are shown in Fig. 6. In IR region, many low-angle boundaries (misorientation angle $<5^{\circ}$ ) are present in the ferrite and austenite grains. The frequency of low-angle boundaries increases faster in the aged materials than in the unaged samples. For the ferrite phase, the high-angle boundaries $\left(5^{\circ}<\right.$ misorientation angle $<15^{\circ}$ ) decrease after thermal aging, as shown in Fig. 6a, b. The frequency distribution of higher-angle boundaries has no obvious difference in the three deformation regions. For the austenite phase, the frequency distribution of low-angle boundaries and high-angle boundaries is similar to the ferrite phase, as shown in Fig. $6 c, d$.

The strain contouring mappings in the three different deformation regions are obtained from EBSD analysis of the unaged and aged specimens, as shown in Fig. 7. The local misorientation angle indicates the micro-strain of the sample. High values of micro-strain and phase boundary are indicated by yellow regions and red lines, respectively.
In IR region, high values of micro-strain regions are dominant in all the ferrite and austenite grains for unaged samples, as shown in Fig. 7a. A large number of yellow regions are also observed near the phase boundaries for the unaged materials. Compared with the unaged ferrite grains, more blue regions in aged ferrite grains are observed in IR region, as shown in Fig. 7d. As the deformation proceeds, a large number of high-micro-strain regions develop nearby the austenite grain boundaries or phase boundaries for the unaged materials, as shown in Fig. 7b. Compared with the unaged samples, more blue regions are observed in the austenite and ferrite grains for the aged materials in IIR and IIIR regions, as shown in Fig. 7e, f. In IIIR region, more blue regions are observed in both austenite and ferrite grains for the unaged materials, as shown in Fig. 7c. As shown in Fig. 7, the fraction of yellow regions decreases in IIIR region compared with IIR region. The IIR and IIIR regions correspond to the crack propagation stage and the near final fracture stage of impact deformation, respectively. These micro-strain regions nearby the austenite grain boundaries or the phase boundaries correspond to the distribution of the grain boundaries in Fig. 5. After thermal aging, cracks initiated at the phase boundaries have more opportunities to expand to the ferrite grains due to the hardening of aged ferrite grains. The fraction of yellow regions continuously decreases in IIR and IIIR regions.

The distribution of strain in different deformation regions of the unaged and aged samples is shown in Fig. 8. For the ferrite phase, it is clear that the frequency of lowlocal strain areas (local misorientation angle $<1^{\circ}$ ) increases with deformation process. At the same time, the frequency of low-local strain areas increases in various deformation regions after thermal aging, as shown in Fig. 8a. For the unaged samples, the frequency of highlocal strain areas (local misorientation angle $>2^{\circ}$ ) 

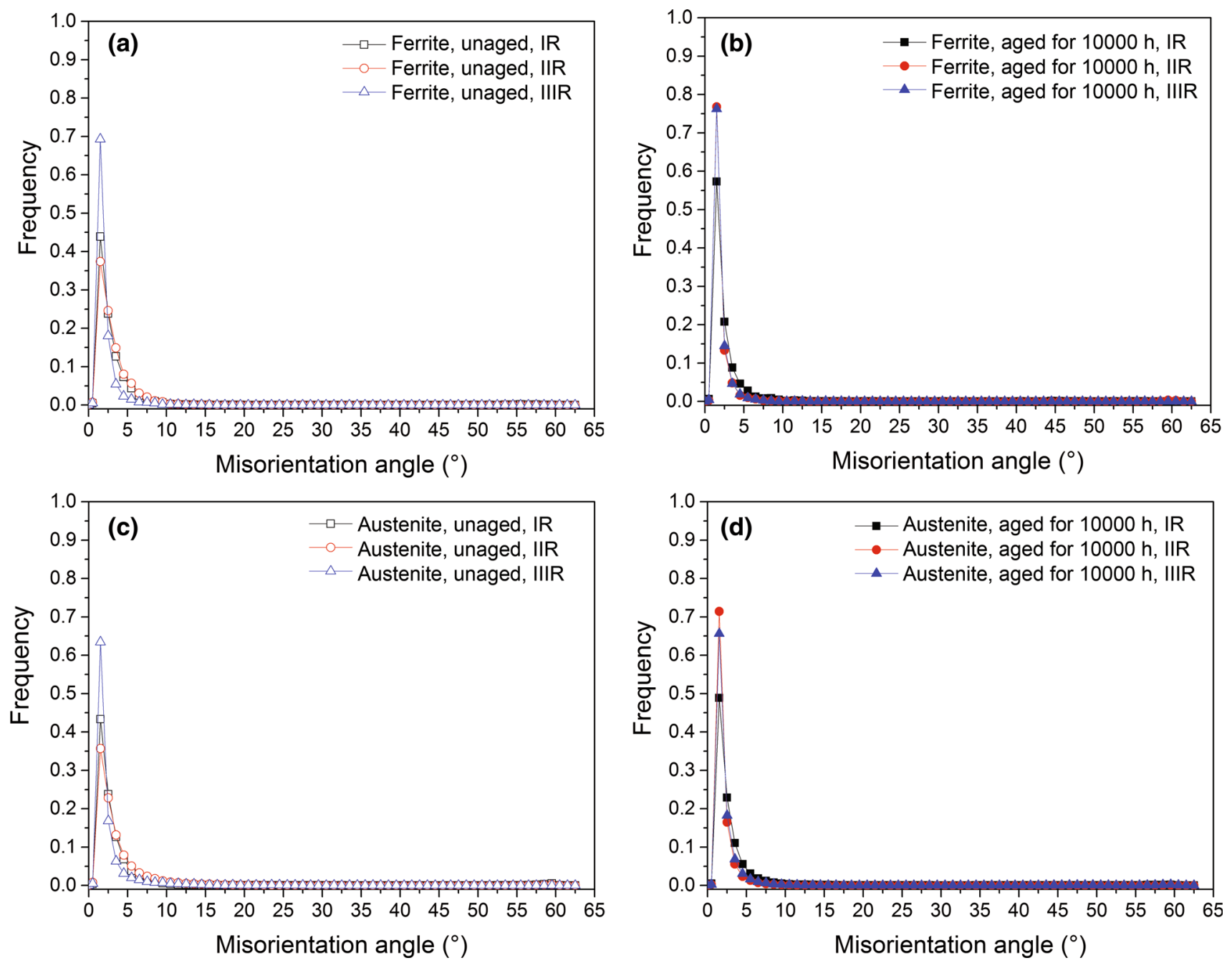

Fig. 6 Distribution of misorientation angle in three regions deformed differently: a ferrite phase in unaged samples; $\mathbf{b}$ ferrite phase in aged samples; $\mathbf{c}$ austenite phase in unaged samples; $\mathbf{d}$ austenite phase in aged samples
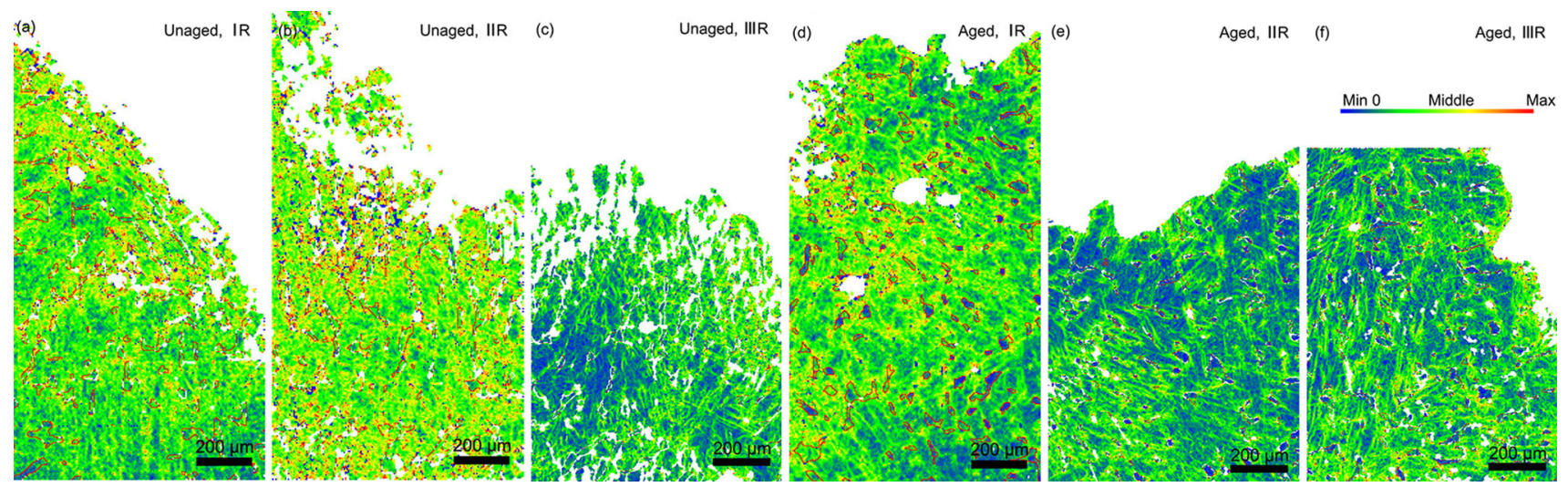

Fig. 7 Strain contouring mappings in three regions: a unaged at IR; b unaged at IIR; $\mathbf{c}$ unaged at IIIR; d aged for 10,000 h at IR; e aged for $10,000 \mathrm{~h}$ at IIR; $\mathbf{f}$ aged for 10,000 $\mathrm{h}$ at IIIR (red lines: phase boundaries; yellow region: high value of micro-strain)

decreases with deformation process. To compare with the unaged ferrite grains, the frequency of high-local strain areas decreases faster in the aged ferrite grains.
For the austenite phase, it is clear that the frequency of low-local strain areas increases with deformation process for both the unaged and the aged samples. After thermal 

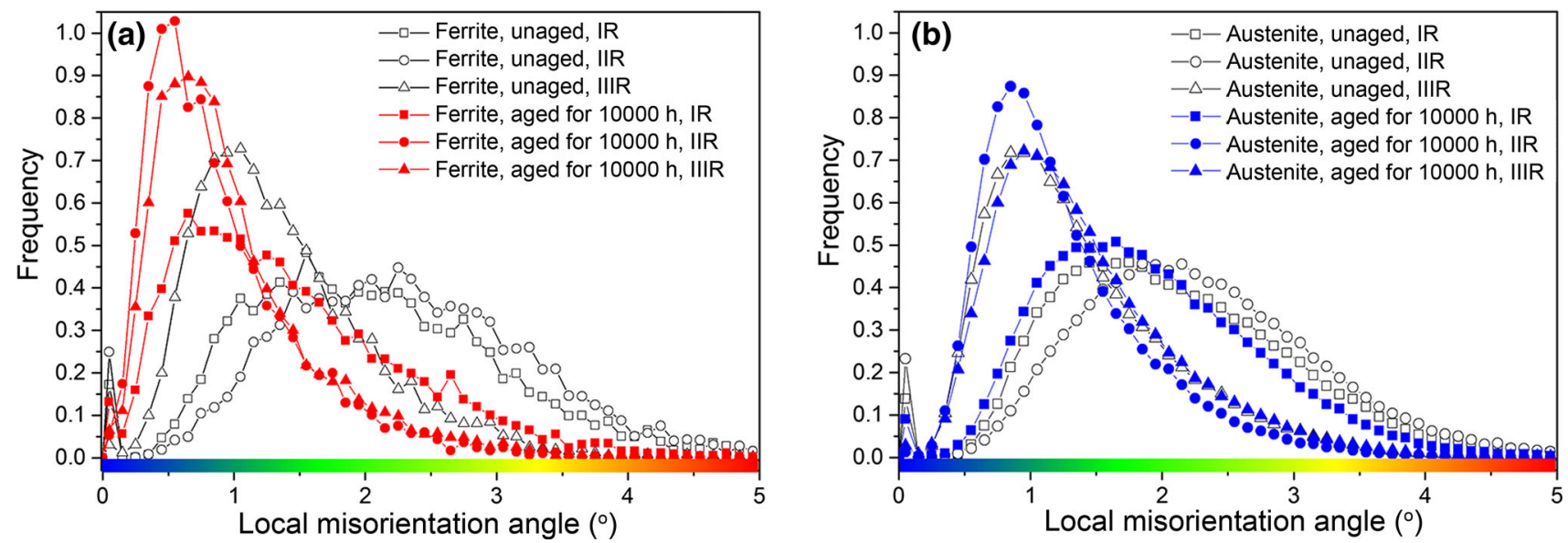

Fig. 8 Distribution of strain values in three regions: a ferrite phase in unaged and aged samples; $\mathbf{b}$ austenite phase in unaged and aged samples

aging, more low-local strain areas and fewer high-local strain areas are observed in IIR region, as shown in Fig. 8b. In IR and IIIR regions, the distributions of local misorientation in the austenite grains are almost the same for both the unaged and the aged materials.

As shown in Fig. 8, the strain in IIR is larger than in IIIR region. The frequency of low micro-strain $\left(0.5^{\circ}<\right.$ local misorientation angle $<1.5^{\circ}$ ) in IIR is larger than in IIIR region. The IIR region corresponds to the crack propagation stage of impact deformation. After thermal aging, the fraction of blue area in IIR region continuously increases with deformation process. However, the strain in IIIR region decreases and the cracks propagate more easily due to the hardening of aged ferrite grains. Meanwhile, the frequency in the unaged phases is lower than that in the aged phases. The aged ferrite and austenite phases have lower-micro-strain areas more than the unaged phases due to the aging embrittlement.

\subsection{TEM Analysis Near the Fractures}

Figure $9 \mathrm{a}, \mathrm{b}$ shows the microstructures of ferrite phase for the unaged and aged materials before deformation. The corresponding electron diffraction (ED) and fast Fourier transformation (FFT) patterns of the ferrite are also shown. For the unaged samples, no precipitation is found in ferrite, as shown in Fig. 9a. The microstructures of aged ferrite phase and precipitated particles are shown in Fig. 9b. The precipitated particles are identified as G-phases and the mottled contrast precipitates indicate that the ferrite phases decomposed into Fe-rich $\alpha$ and $\mathrm{Cr}$-enriched $\alpha^{\prime}$, which agrees with those previously reported $[14,15]$.

The TEM images of the ferrite and the austenite phases in the unaged materials after deformation are shown in Fig. 9c. Multiple dislocations are observed in the ferrite and austenite phases, as shown in Fig. 9c. These dislocations along the phase boundaries could pass through the ferrite-austenite boundaries as the deformation proceeds. After thermal aging, spinodal decomposition precipitates and G-phase precipitates have an effect on the dislocation movement, as shown in Fig. 9d. The pinned dislocations in the ferrite and along the phase boundaries lead to high stress concentration, causing crack initiation in the aged ferrite phase. However, the blocking influence of these precipitates is stronger than the effect of the grain boundaries and the phase boundaries on the dislocation movement. After thermal aging, micro-cracks preferentially initiate in the ferrite phase.

\section{Conclusions}

The effect of long-term thermal aging on impact deformation behavior of the Z3CN20-09M duplex stainless steel was studied. The main conclusions are drawn as follows:

1. After long-term thermal aging, the impact toughness decreases significantly and the cracks initiate and propagate more easily. The plastic deformation ability of the ferrite phase decreases.

2. High-stress concentration areas are observed near the phase boundaries and the austenite grain boundaries in the aged materials. Cracks initiated at the phase boundaries have more opportunities to expand to the ferrite grains due to the hardening of aged ferrite grains.

3. The effect of thermal aging on deformation ability of the ferrite leads to the degradation of impact property. After long-term thermal aging, the pinned dislocations 

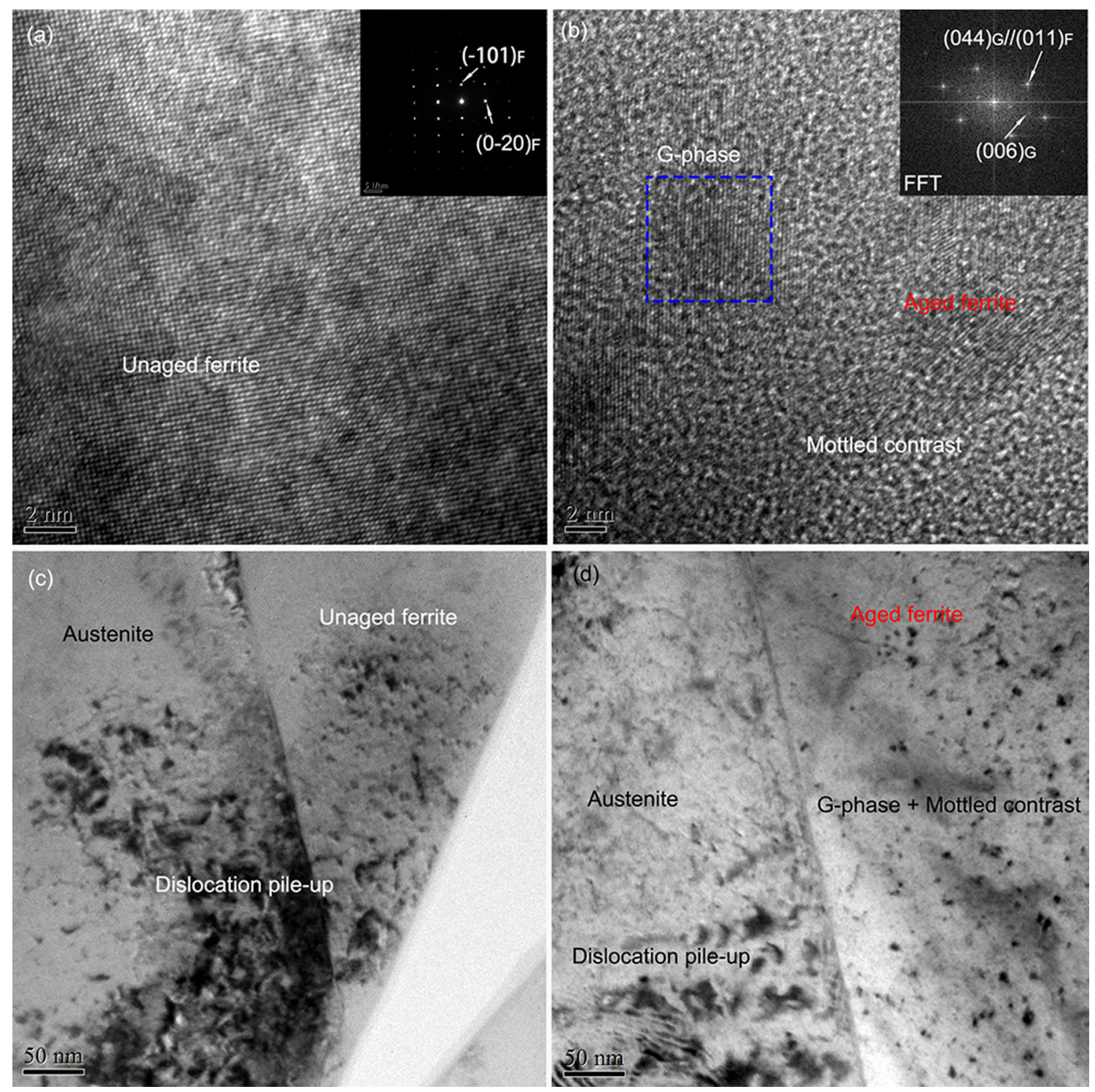

Fig. 9 TEM images in ferrite and austenite phases of specimens: a ferrite phase in unaged samples; b ferrite phase in aged samples; c deformation areas in unaged samples; d deformation regions in samples aged at $400{ }^{\circ} \mathrm{C}$ for $10,000 \mathrm{~h}$

in the ferrite and along phase boundaries lead to the high stress concentration.

4. The blocking influences of spinodal decomposition precipitates and G-phase precipitates are stronger than those of grain boundaries and phase boundaries on the dislocation movement. Micro-cracks preferentially initiate in the ferrite phase.

Acknowledgements This work was financially supported by the National High Technology Research and Development Program of China (863 Program), National High-tech R\&D Program of China (No. 2015AA03A502), the National Natural Science Foundation of China (No. 51601013), the Beijing Natural Science Foundation (No. 2174080) and the Fundamental Research Funds for the Central Universities (No. FRF-TP-16-025A3).

\section{References}

[1] P. McConnell, W. Sheckherd, D. Norris, J. Mater. Eng. 11, 227 (1989)

[2] M. Bethmont, Y. Meyzaud, P. Soulat, Int. J. Press. Vessels Pip. 65, 221 (1996)

[3] J.J. Shiao, C.H. Tsai, J.J. Kai, J.H. Huang, J. Nucl. Mater. 217, 269 (1994)

[4] H.M. Chung, Int. J. Press. Vessels Pip. 50, 179 (1992)

[5] M.D. Mathew, L.M. Lietzan, K.L. Murty, V.N. Shah, Mater. Sci. Eng. A 269, 186 (1999)

[6] S.L. Li, Y.L. Wang, X.T. Wang, F. Xue, J. Nucl. Mater. 452 , 382 (2014)

[7] L. Devillers-Guerville, J. Besson, A. Pineau, Nucl. Eng. Des. 168, 211 (1997)

[8] P. Haušilda, C. Berdina, P. Bompard, N. Verdiere, Int. J. Press. Vessels Pip. 78, 607 (2001) 
[9] L. M'cirdi, J.L. Lebrun, K. Inal, G. Barbier, Acta Mater. 49, 3879 (2001)

[10] J.D. Kwon, S.W. Woo, Y.S. Lee, J.C. Park, Y.W. Park, Nucl. Eng. Des. 206, 35 (2001)

[11] K. Chandra, V. Kain, V.S. Raja, R. Tewari, G.K. Dey, Corros. Sci. 54, 278 (2012)

[12] N. Jia, R.L. Peng, G.C. Chai, S. Johansson, Y.D. Wang, Mater. Sci. Eng. A 491, 425 (2008)

[13] K. Seiichi, S. Naruo, T. Genta, Nucl. Eng. Des. 174, 273 (1997)

[14] S.L. Li, Y.L. Wang, S.X. Li, H.L. Zhang, F. Xue, X.T. Wang, Mater. Des. 50, 886 (2013)
[15] S.L. Li, Y.L. Wang, H.L. Zhang, S.X. Li, K. Zheng, F. Xue, X.T. Wang, J. Nucl. Mater. 433, 41 (2013)

[16] T.S. Byun, Y. Yang, N.R. Overman, J.T. Busby, JOM 68, 507 (2016)

[17] K.L. Weng, H.R. Chen, J.R. Yang, Mater. Sci. Eng. A 379, 119 (2004)

[18] O.H. Ibrahim, I.S. Ibrahim, T.A.F. Khalifa, J. Mater. Sci. Technol. 26, 810 (2010)

[19] K. Chandra, V.D. Kain, V. Bhutani, V.S. Raja, R. Tewari, G.K. Dey, J.K. Chakravartty, Mater. Sci. Eng. A 534, 163 (2012)

[20] A. Ghosh, S. Kundu, D. Chakrabarti, Scr. Mater. 81, 8 (2014) 